\title{
A Manufacturing Model for Ball-End Mill Gashing Based on a CAM System
}

\author{
Fei Tang ${ }^{*}, 1$, Min Jin ${ }^{1}$, Xiaofeng Yue ${ }^{2}$, Zhanhua You ${ }^{2}$, Shuzhe $\mathrm{Li}^{1}$ and Xiaohao Wang ${ }^{1}$ \\ ${ }^{I}$ State Key Laboratory of Precision Measurement Technology and Instruments, Department of Precision Instruments \\ and Mechanology, Tsinghua University, Beijing, 100084, China \\ ${ }^{2}$ School of Electronics and Computer Science and Technology, North University of China, Taiyuan, Shanxi, 030051, \\ China
}

\begin{abstract}
To facilitate the manufacturing of a ball-end mill, this paper presents an algorithm for ball-end mills gashing by using a five-axis computer numerical control (CNC) grinding machine. In this study, the normal helix models are proposed. Then, based on the cutting edge geometric model and the machining mode of the five-axis computer numerical control (CNC) grinding machine, the coordinate of the grinding point when the step of the gash out is grinded will be calculated. With the input data of ball-end mill geometry, wheels geometry, wheel setting and machine setting, the NC code for machining will be generated. Then the code will be used to simulate the ball-end mill machining in 3 Dimension. The 3D simulation system of the ball-end mill grinding is generated by VBA and AutoCAD2008. The algorithm of ballend mill gashing can be verified by the 3D simulation system. Result shows that the algorithm presented in this paper provides a practical and efficient method for the manufacture of a ball-end mill gashing.
\end{abstract}

Keywords: CNC grinding, ball-end mill, gash out, grinding wheel.

\section{INTRODUCTION}

The ball-end mills used in a Computer Numerical Control (CNC) machine play a vital role in a successful High-Speed Machining (HSM) process, which directly affect the quality of a machined surface [1]. In order to save time and reduce the cost of manufacturing process, it is necessary to control the prediction of the ball-end mill geometry .In addition, there is a need to develop a cutting tool with high performance and long product life with low price. The shape of a ball-end mill contributes a lot to machining accuracy and dynamic stability, and it is defined by a few elements like relief angle, rake angle, and helix angle. The grinding of a ball-end mill with a complex geometry is related to some complicated processes in machining with a $\mathrm{CNC}$ grinding machine. Therefore, the research on the helical-groove grinding, the cutting tool manufacturing and the cutting edge geometric model has drawn great interest of many researchers $[2,3]$. When traditional design method is used to determine the structure and the parameters of a ball-end mill, the designers need to access large amounts of data and rules. Not only the design cycle time is long, but also it is hard to control the quality of the design. To reduce the cost and save the time for designing a ball-end mill, a 3D solid model is used.

One key feature of modern CAD/CAM system is the automatic generation of NC-machining programs directly from a CAD model $[4,5]$. In our CAM system, the NC code

*Address correspondence to this author at the State Key Laboratory of Precision Measurement Technology and Instruments, Department of Precision Instruments and Mechanology, Tsinghua University, Beijing, 100084, China; Tel: ++86-10-62796216(office); +86-13911582973 (Mobile); Fax: +86-10-62796707; E-mail: tangf@mail.tsinghua.edu.cn of all processes for the ball-end mill manufacturing is generated automatically in the program based on its 3D solid model. These NC code files will be loaded for machining in the CNC grinding machines. It is necessary to verify the performance of the NC code before actual manufacturing. However, traditional CAM systems cannot provide the method to realize this type of simulations and specific applications. The algorithm of producing a ball-end mill can be authenticated by the 3D simulation system. This paper presents how to calculate the grinding data of gash, and how to generate and simulate $\mathrm{NC}$ code for all grinding processes in $3 \mathrm{D}$ manner.

\section{THE SETTING OF MACHINE REFERENCE FRAME AND BALL-END MILL GEOMETRY}

In the study, the ball-end mill is machined on the $\mathrm{CNC}$ grinding machine tool, which has 5 degrees of freedom: three axes in translation (X-axis, Y-axis, and Z-axis) and two in rotation (A-axis, $\mathrm{C}$-axis). The machine coordinate system is established as shown in Fig. (1). When the C-axis coordinate is 0 , the axial direction of the end mill is in accordance with $\mathrm{X}$-axis. The wheel spindle is $\mathrm{Y}$-axis. The origin of coordinates is the intersections of $\mathrm{X}$-axis and $\mathrm{Y}$ axis. Z-axis is vertical with $\mathrm{XY}$ plane. The tool is fixed on the tool holder, which has three degrees of freedom; two rotation (A-axis, C-axis) and translation (X-axis). The grinding wheels are arranged at the wheel spindle, which has two degrees of freedom; translation (Y-axis) and translation (Z-axis). Fig. (2) shows the arrangement of the grinding wheels for the ball-end mill manufacturing. There are four major machining steps for the ball-end mill manufacture: fluting, first and second reliefs, gashing out, and tip clearance. Wheel 1 and 2 are used for the operation of the 
gash out and the flute. Wheel 3 is used for the first and the second relief operations. The tip clearances are performed by wheel 2.

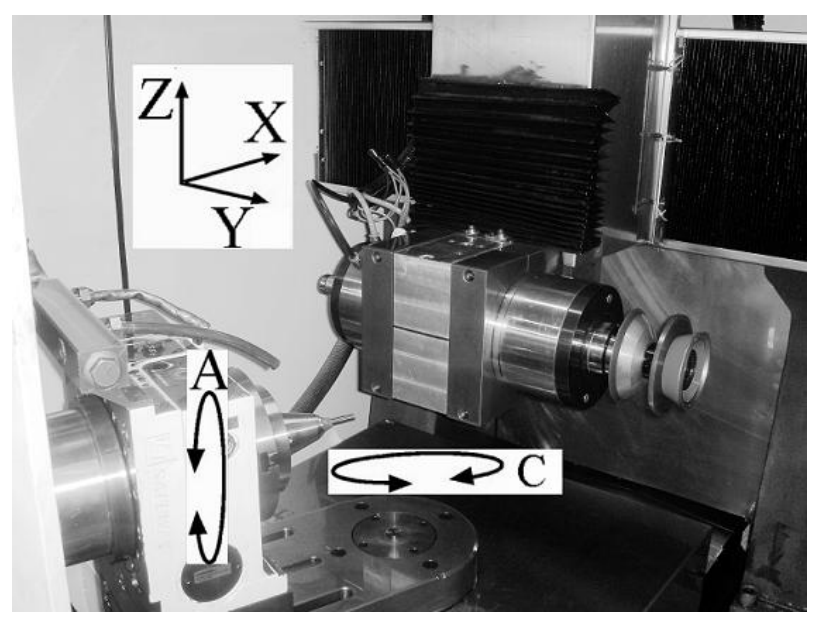

Fig. (1). The applied five-axis grinding machine.

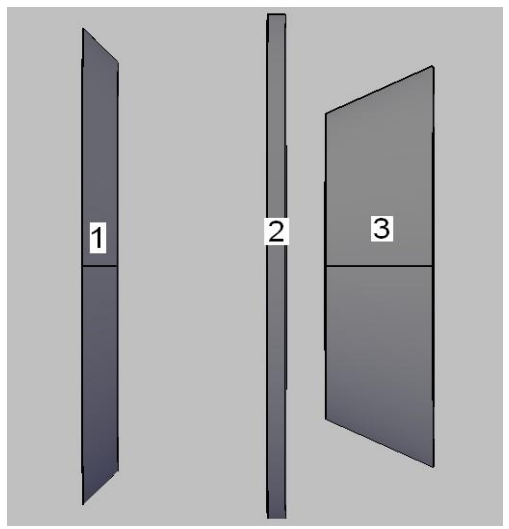

Fig. (2). Grinding wheels for ball-end millmanufacturing.

\subsection{Dimensional Parameters}

Fig. (3), Fig. (4) and Table 1 show the geometric dimensions that define the shape of the ball-end mills. It should be noted that the helical groove and the neck groove shape will not be determined by the design parameters but by other factors, such as the grinding wheel shape and the grinding position. In general, the geometry of a ball-end mill consists of two parts: the geometries of the flute surface and the ballend surface.

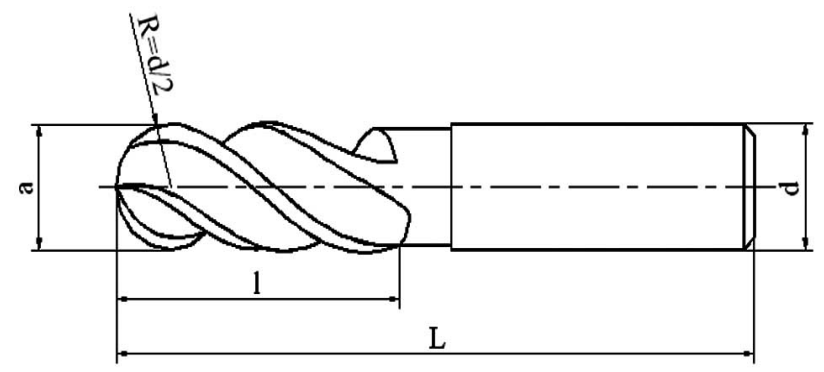

Fig. (3). External shape dimensions of ball-end mill.

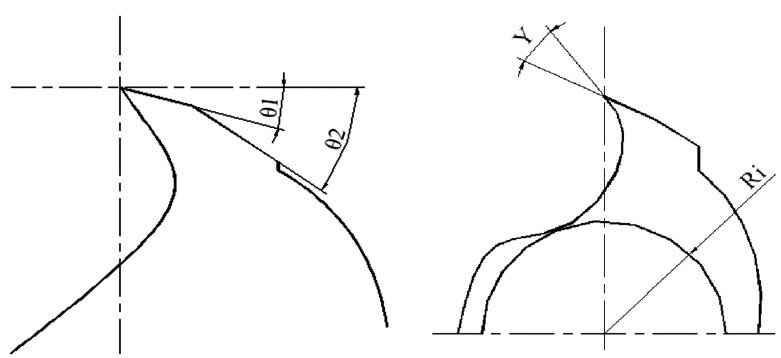

Fig. (4). Section dimensions of ball-end mill.

Table 1. Parameters to Define a Ball-End-Milling Cutter Dimensions

\begin{tabular}{|c|c|c|c|}
\hline$\Phi_{1}$ & First relief angle & 1 & Cutter length \\
\hline$\Phi_{2}$ & Second relief angle & $\beta$ & Helix angle \\
\hline$\Gamma$ & Rake angle & $\mathrm{N}_{\mathrm{f}}$ & Number of flutes \\
\hline $\mathrm{R}_{\mathrm{i}}$ & Radius of inner circle & $\mathrm{D}_{1}$ & Shank diameter \\
\hline $\mathrm{d}$ & Cutter diameter & $\mathrm{L}_{\mathrm{s}}$ & Shank length \\
\hline $\mathrm{L}$ & Overall length & $\mathrm{R}$ & Ball end radius \\
\hline$\theta_{1}$ & First ball-end relief angle & $\theta_{2}$ & Second ball-end relief angle \\
\hline
\end{tabular}

\subsection{Basic Algorithm for a Ball-End Mill Grinding}

The machining of a cutting tool is to be done with sets of operation steps, each of which has a specific name in the CNC jargon. Each operation is performed with dedicated wheel. This information is contained in the CNC file. Specifically, the main steps are (in their usual order): Helical-flute, Relief angle and Gashing. The mathematical models for the helical flute and the gash out machining are based on the enveloping theory and the fundamental analytical conditions of engagement between the wheel surface and the helical groove surface [6]. As shown in Fig. (5), an independent right hand Cartesian coordinate system other than the system created for the $\mathrm{CNC}$ machine is established. Origin $\mathrm{O}$ is in the ball centre of the ball-end mill, $\mathrm{X}$-axis is the axial direction of the end mill, cylindrical and ball junction plane is $\mathrm{YOZ}$ surface, $\mathrm{Z}$-axis has an intersection with the cutting edge geometric curve. The cutting edge geometric curve can be considered as the intersection between an orthogonal helical surface and a ball surface. We use $\vec{r}$ to represent the cutting edge curve on the orthogonal helical surface, which can be expressed as:

$$
\vec{r}=\left\{\begin{array}{l}
X=\frac{P}{2 \pi} \phi \\
Y=R \cos \theta \sin \phi \\
Z=R \cos \theta \cos \phi
\end{array}\right.
$$

Where $\mathrm{X}, \mathrm{Y}, \mathrm{Z}$ stand for 3-dimention coordinates, $\beta$ is the helix angle, $\mathrm{R}$ is the radius of the ball-end mill, $\mathrm{P}$ is the lead value, and $\varphi$ is the angle between the any point on the cross section to the center and the $\mathrm{X}$ axis. The equation of ball can be expressed as: 


$$
\vec{r}=\left\{\begin{array}{l}
X=R \sin \theta \\
Y=R \cos \theta \sin \phi \\
Z=R \cos \theta \cos \phi
\end{array}\right.
$$

Where $\mathrm{R}$ is the radius of the ball-end mill, $\theta$ and $\varphi$ are parameters. From the theory of normal helix, we know that $P=2 \pi R / \tan \beta$. Combine this with the equation (1) and (2), the cutting edge geometric model of the ball-end mill can be derived, which can be expressed as:

$$
\vec{r}=\left\{\begin{array}{l}
X=R c \phi \\
Y=R \sqrt{1-(c \phi)^{2}} \sin \phi \\
Z=R \sqrt{1-(c \phi)^{2}} \cos \phi
\end{array}\right.
$$

Where $\mathrm{c}=1 / \tan \beta, \beta$ is the helix angle, $\mathrm{R}$ is the radius of the ball-end mill, $\varphi$ is the angle between the any point $\mathrm{P}$ on the cross section to the center and the $\mathrm{X}$ axis. $0 \leq \phi \leq \tan \beta$.

Per the knowledge of differential geometry, the tangent vector $T$ of the any point $\mathrm{P}$ on the cutting edge can be deduced as:

$$
\vec{T}=\left[\begin{array}{c}
T_{X} \\
T_{Y} \\
T_{Z}
\end{array}\right]=\left[\begin{array}{l}
\frac{d X}{d \phi} \\
\frac{d Y}{d \phi} \\
\frac{d Z}{d \phi}
\end{array}\right]=\left[\begin{array}{l}
c R \\
-\frac{R\left(\cos \phi \cdot c^{2} \cdot \phi^{2}+\sin \phi \cdot c^{2} \cdot \phi-\cos \phi\right)}{\sqrt{1-(c \phi)^{2}}} \\
\frac{R\left(\sin \phi \cdot c^{2} \cdot \phi^{2}+\cos \phi \cdot c^{2} \cdot \phi-\sin \phi\right)}{\sqrt{1-(c \phi)^{2}}}
\end{array}\right]
$$

The unit tangent vector $\vec{T}_{0}=\frac{\vec{T}}{|\vec{T}|},|\vec{T}|$ is expressed as:

$|\vec{T}|=\sqrt{T_{X}^{2}+T_{Y}^{2}+T_{Z}^{2}}=\frac{R \cdot \sqrt{\left(1-c^{2} \cdot \phi^{2}\right)^{2}+c^{2}}}{\sqrt{1-(c \phi)^{2}}}$

Substituting equation (5) into equation (4), the unit tangent vector of the any point $\mathrm{P}$ on the cutting edge becomes:

$$
\left|\vec{T}_{0}\right|=\left[\begin{array}{l}
\vec{T}_{O X} \\
\vec{T}_{O Y} \\
\vec{T}_{O Z}
\end{array}\right]=\left[\begin{array}{l}
\frac{\sqrt{1-(c \phi)^{2}}}{R \cdot \sqrt{\left(1-c^{2} \cdot \phi^{2}\right)^{2}+c^{2}}} \\
-\frac{\cos \phi \cdot c^{2} \cdot \phi^{2}+\sin \phi \cdot c^{2} \cdot \phi-\cos \phi}{R \cdot \sqrt{\left(1-c^{2} \cdot \phi^{2}\right)^{2}+c^{2}}} \\
\frac{\sin \phi \cdot c^{2} \cdot \phi^{2}+\cos \phi \cdot c^{2} \cdot \phi-\sin \phi}{R \cdot \sqrt{\left(1-c^{2} \cdot \phi^{2}\right)^{2}+c^{2}}}
\end{array}\right]
$$

In addition, in the direction of the ball meridian line, the vector of the any point $\mathrm{P}$ on the cutting edge can be expressed as:

$$
\vec{r}_{\theta}=\frac{\partial \vec{r}}{\partial \theta}=\left[\begin{array}{l}
R \cdot \sqrt{1-c^{2} \cdot \phi^{2}} \\
-R \cdot c \cdot \phi \cdot \sin \phi \\
-R \cdot c \cdot \phi \cdot \cos \phi
\end{array}\right]
$$

Then, by the definition of the spiral angle in rotary surface spirals, the spiral angle $\beta$ in the tip ball cutting edge can be deduced as:

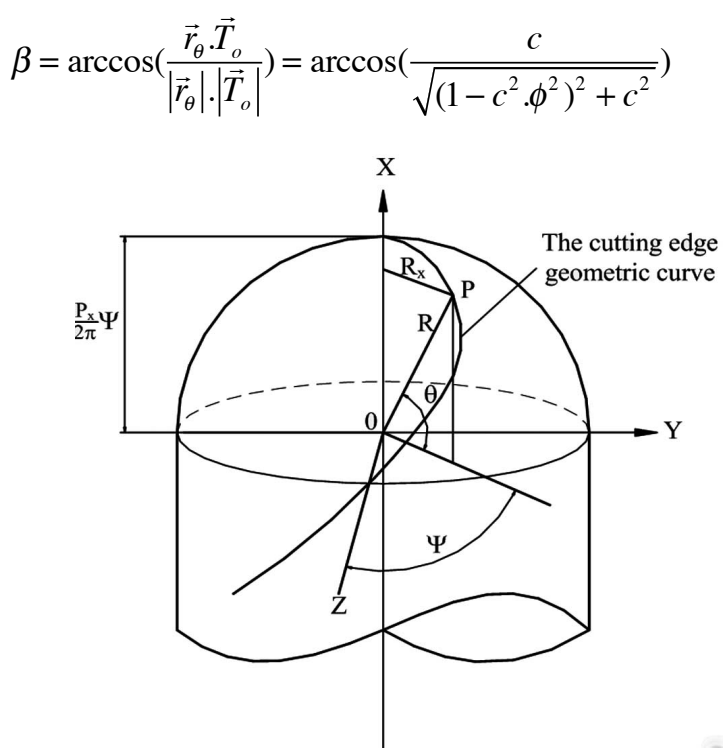

Fig. (5). The cutting edge geometric model of the ball-end mill.

\subsection{The Helical-Gash Out Grinding And The Calculation Of The Grinding Data}

The helical- gash out surface is generated by the combined motion of the grinding wheel 2 and the tool. The gash out surface of the end mill can be formed by the motion of the tool along the curve of the cutting edge and the motion of the grinding wheel 2 along the grinding wheel outline. The shape of the gash out is related to the grinding wheel shape. Fig. (6) shows the schematic illustration of the gashing operation. Differing from other steps, five axes need to move simultaneously in certain matter in this step. The coordinates of contact point between the tool and the wheel will be generated by the CAM system. If the diameter of the end mill, the diameter of the wheel and the location of the wheel is fixed, the contact point data can be calculated accordingly. Table 2 shows the parameters that are used to calculate the coordinate of the contact point.

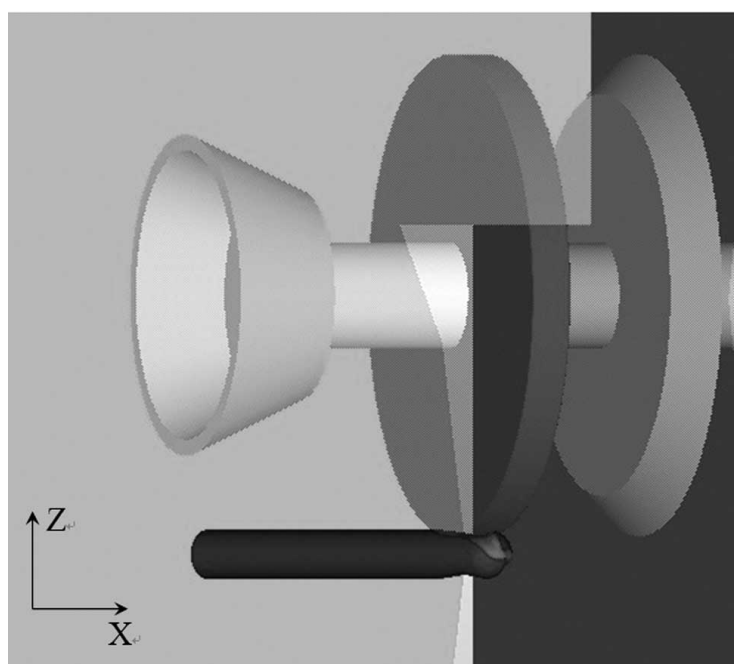

Fig. (6). Schematic illustration of the gashing operation. 
Table 2. Parameters to Calculate the Coordinate of the Contact Point

\begin{tabular}{|c|c|c|c|}
\hline$R$ & Ball end radius & $\mathrm{L}_{2}$ & $\begin{array}{c}\text { Length from X axis zero to C axis } \\
\text { rotation center }\end{array}$ \\
\hline $\mathrm{R}_{1}$ & Wheel radius & $\mathrm{L}_{3}$ & Wheel spindlel length \\
\hline$\theta_{3}$ & Gash out angle & $\mathrm{N}_{\mathrm{f}}$ & Number of flutes \\
\hline$\theta_{4}$ & Gash runout angle & $\mathrm{L}_{4}$ & Grinding wheel flange length \\
\hline $\mathrm{d}$ & Cutter diameter & $\beta$ & Helix angle \\
\hline $\mathrm{L}_{1}$ & Tool holder length & $\mathrm{D}_{2}$ & Core thick diameter \\
\hline
\end{tabular}

There are two ways of processing gash out, one is from the ball head root to the ball head end, and the other is from the ball head end to the ball head root. In this study, the first one is selected. The coordinates of starting contact point can be calculated. Table 3 shows the starting contact point coordinate between the tool and the grinding wheel. In the gash out grinding process, the tool rotates along the A-axis from its original position to 0 , along the $\mathrm{C}$-axis from $-\beta$ to 0 and also moves in the $\mathrm{X}$ directions to find the contact point of the gash out grinding process. At the same time, wheel 2 moves in the $\mathrm{Y}, \mathrm{Z}$ directions to avoid the possible collision to the cutting tool.

Table 3. The Starting Contact Point Coordinate between the Tool and the Grinding Wheel

\begin{tabular}{|c|c|}
\hline $\mathrm{C}_{0}$ & $\operatorname{acos}\left(c / \sqrt{\left(1-c^{2} \cdot \phi^{2}\right)^{2}+c^{2}}\right)$ \\
\hline $\mathrm{X}_{0}$ & $\left(-L_{2}+L_{1}-R\right) \cdot \cos C_{0}+L_{2}+R_{1} \cdot \sin \theta_{4}$ \\
\hline $\mathrm{Y}_{0}$ & $-\left(-L_{2}+L_{1}-R\right) \cdot \sin C_{0}-L_{4}-L_{3}$ \\
\hline $\mathrm{Z}_{0}$ & $R_{1} \cdot \cos \theta_{4}+D_{2} / 2$ \\
\hline $\mathrm{A}_{0}$ & $\tan \beta$ \\
\hline $\mathrm{c}$ & $1 / \tan \beta$ \\
\hline
\end{tabular}

Table 4 shows the calculation of the grinding data for gash out grinding:

Through the above calculation, the CAM system can automatically generate $\mathrm{NC}$ code. Users input the parameters in the dialog box of ball-end mill grinding program, then the corresponding NC machining code can be automatically generated.

Table 4. The Calculation of the Grinding Data for Gash Out Grinding

\begin{tabular}{|c|c|}
\hline $\mathrm{T}_{1}$ & $90^{\circ}-\theta_{3}-\theta_{4}$ \\
\hline $\mathrm{t}$ & Change from 0 to $\mathrm{T}_{1}$ \\
\hline $\mathrm{A}_{1}$ & $\mathrm{t} \cdot \tan \beta / T_{1}$ \\
\hline $\mathrm{C}_{1}$ & $\operatorname{acos}\left(c / \sqrt{\left(1-c^{2} \cdot A_{1}^{2}\right)^{2}+c^{2}}\right)$ \\
\hline $\mathrm{X}_{1}$ & $R_{1} \sin \left(\theta_{3}+t\right)+R \cdot A_{1} \cdot c+\left(-L_{2}+L_{1}-R\right) \cos C_{1}$ \\
\hline $\mathrm{Y}_{1}$ & $\left(-L_{2}+L_{1}-R+R \cdot A_{1} \cdot c\right) \sin C_{1}$ \\
\hline $\mathrm{Z}_{1}$ & $R_{1} \cdot \cos \left(\theta_{3}+\mathrm{t}\right)+\left(R-R \cdot A_{1} \cdot c\right) \cdot\left(D_{2} / 2\right) / R$ \\
\hline $\mathrm{c}$ & $1 / \tan \beta$ \\
\hline
\end{tabular}

\section{DESIGN SIMULATION SYSTEM BASE ON BOOLEAN OPERATIONS}

The representation of 3D CAD model forms the basic cornerstone of the computer controlled manufacturing process. We develop the simulation system on the basis of AutoCAD2008 Open API and VBA in the MS Windows environment. The main functions applied in this system include the end mill shape modeling, the prediction of wheel geometry and the tool path verification.

According to the machine mechanical structure, the CAM system generates the wheel model and the tool model. In simulation, machining can be considered as a dynamic Boolean operation of difference between the grinding wheel and the tool through NC code $[7,8]$. It is dynamic because that both the tool and the wheels move along through rotations and translations. Then the major design parameters of a cutter, such as relief angle and inner radius, can be verified by interrogating the section profile of its solid model. The movements are divided into blocks; each one corresponds to a $\mathrm{CNC}$ operation or even to one cut within an operation. Each block is performed in sequence of the machining process which has absolute coordinate and relative coordinates.

\section{GRINDING PERFORMANCE AND RESULTS}

\subsection{Generation of NC Codes for Ball-End Mill Machining}

Using the input data for ball-end mill geometry, wheel geometry and machine configuration data, the computer program will generate the grinding points for helical-flute, relief angle and gashing. The $\mathrm{NC}$ codes for manufacturing in 5 -axis CNC grinding machine are generated by the program and stored as txt file. Each machining process is carried out through the rotation and the translation of the axis of the wheel and the tool. The design parameters and cutting conditions of the ball-end mill as example are described in Table 5 .

\section{Table 5. Design Parameters of the Ball-End Mill}

\begin{tabular}{|c|c|c|c|}
\hline Diameter & $6 \mathrm{~mm}$ & First relief angle & $8^{\circ}$ \\
\hline $\begin{array}{c}\text { Radius of inner } \\
\text { circle }\end{array}$ & $1.8 \mathrm{~mm}$ & Second relief angle & $16^{\circ}$ \\
\hline $\begin{array}{c}\text { Number of teeth } \\
\text { Helix angle }\end{array}$ & 2 & First ball-end relief angle & $12^{\circ}$ \\
\hline Rake angle & $10^{\circ}$ & Secondball-end relief angle & $24^{\circ}$ \\
\hline Gash out angle & $35^{\circ}$ & Overall length & $30 \mathrm{~mm}$ \\
\hline
\end{tabular}

\subsection{Simulation Results}

Simulation software works as following:

A. The creation of the scene model starts from a textual description of the wheels and the initial tool.

B. The translation of the $\mathrm{CNC}$ code into a linear list of movement instructions. This step consists of removing loops and alternative structures, filtering unnecessary expressions as well as evaluating variables. 
C. Machining simulation on each block

D. Measurements of the tool on 2D cross-sections.

The NC code is used to simulate all the machining processes in 3D. From Fig. (7) to Fig. (12), they show the toolpath verification procedure in which the solid models in the CAM system are constructed and simulated, and the interference detection is performed, such as the collision between machine components or axis stroke-over. Fig. (7) is showing how to simulate the helical-gash using wheel 2. The Fig. (8) shows the final gashing after grinding. Fig. (9) is the process of grinding the relief angle using the wheel 3. Fig. (10) shows the final relief surface after grinding. Fig. (11) is the process of grinding the Helical-gashing after grinding, relief angle and tip clearance operations. Fig. (12) is the final cutter after grinding.

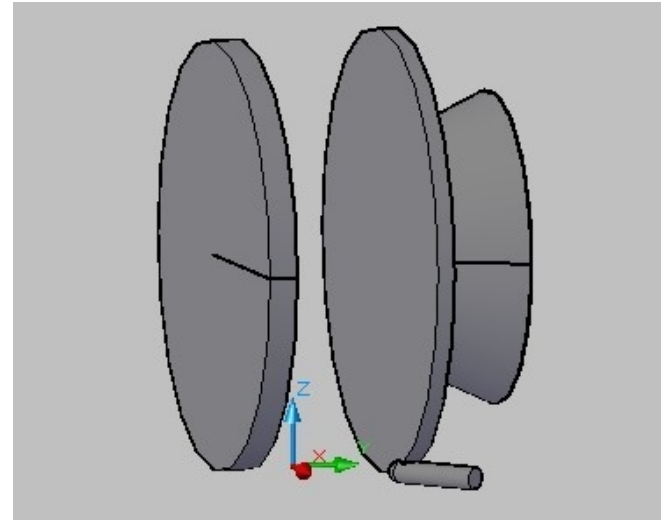

Fig. (7). The grinding of Helical-gashing.

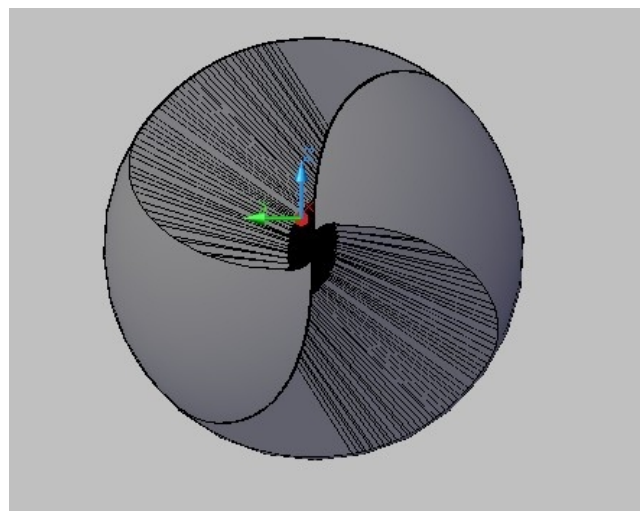

Fig. (8). The final gash after grinding.

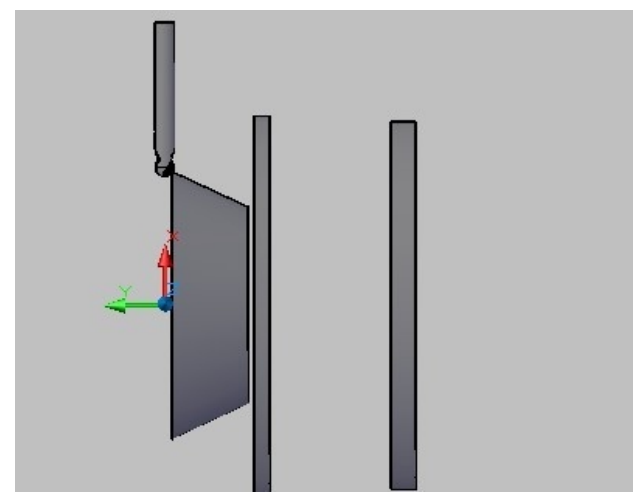

Fig. (9). The grinding of relief angle.

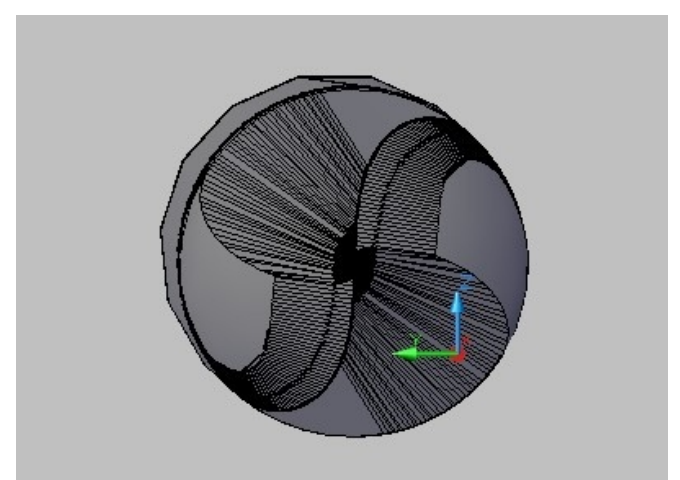

Fig. (10). The final relief after grinding.

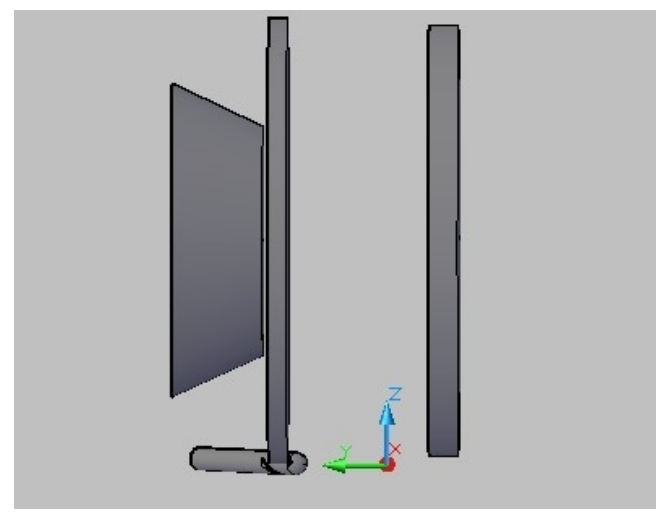

Fig. (11). The grinding of Helical-gashing.

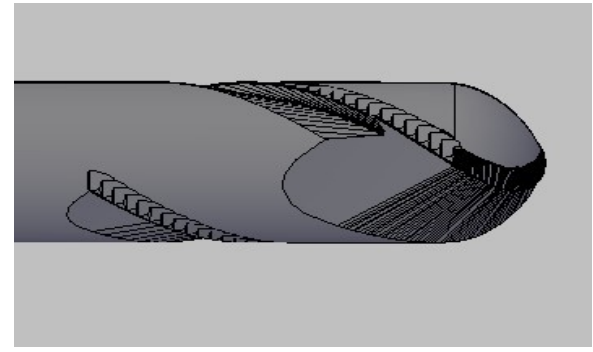

Fig. (12). A final cutter after grinding.

\subsection{Experiment Results}

From above example of simulation, we can see that this model can well describe a cutting tool with computer language. This allows engineers to try and study different shape and geometry of ball-end mill tool before doing any real grinding work. The cycle time and material cost of developing new ball-end mill tool is reduced dramastically.

Fig. (13) is the ball-end mill sample produced by a CNC machine based on the simulation result discussed in the paper. The physical tool matches the simulation result of manufacturing model very well.

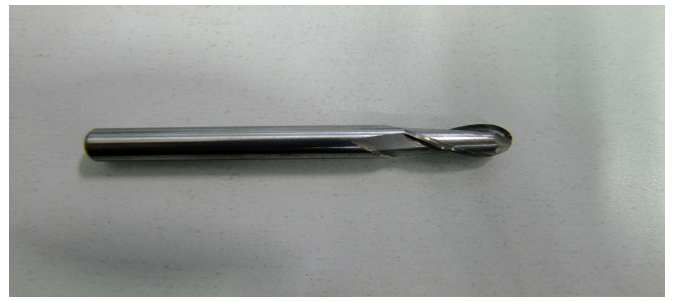

Fig. (13). Sample of a ball-end mill machined by the developed software. 


\section{CONCLUSIONS}

The paper presents a new method which is used to grind the gashing out of the ball-end mill. The calculation, simulation and experiment results indicate that the manufacturing model presented in this paper provides a simple and efficient method of fabricating a grinding end mill. The CAM system is developed to predict and optimize geometric ball-end mill configuration before machining. The $\mathrm{NC}$ codes for all steps of manufacturing in 5-axis $\mathrm{CNC}$ grinding machine are generated from the CAM software for the CNC machine. It is necessary to simulate ball-end mill geometry and verify the NC code before processing the real materials to save time and to reduce the manufacturing cost. The developed CAM system has been used to manufacture ball-end mills together with the developed five-axis $\mathrm{CNC}$ grinding machine.

\section{CONFLICT OF INTEREST}

None declared.

\section{REFERENCES}

[1] Reuteler, "Cutting tool technology in high-speed milling (HSM)", FRAISA SA, 1997.

[2] W. Zhang, X. Wang, F. He, and D. Xiong, "A practical method of modelling and simulation for drill fluting", Int. J. Mach. Tools. Manuf., vol. 46, pp. 667-672, 2006.

[3] J. Hsieh, "Mathematical model and sensitivity analysis for helical groove machining", Int. J. Mach. Tools. Manuf., vol. 46, pp. 10871096, August 2006.

[4] Y. Lu, Y. Takeuchi, I. Takahaki, and M. Anzai, "An integrated system development for ball end mill design, creation and evaluation", Int. J. Adv. Manuf. Tech., vol. 25, pp. 628-646, 2005.

[5] S.L. Ko, T.T. Pham, and Y.H. Kim, "Visualization process for design and manufacturing of ball-end mills", LNAI, SpringerVerlag: Berlin Heidelberg, vol. 3613, pp. 1133, 2008.

[6] T.T. Pham, and S.L. Ko, "A practical approach for simulation and manufacturing of a ball-end mill using a 5-axis CNC grinding machine", J. Mech. Sci. Technol., vol. 24, pp. 159-163, 2010.

[7] D. Tost, A. Puig, and L.P. Vidal, "Boolean operations for 3D simulation of CNC machining of drilling tools", Comput.-Aided Des., vol. 36, pp. 315-323, 2004.

[8] J.H. Kim, J.W. Park, and T.J. Ko, "End mill design and machining via cutting simulation", Comput.-Aided Des., vol. 40, pp. 324-333, 2008 .

\section{ACKNOWLEDGEMENT}

None declared.

(C) Tang et al.; Licensee Bentham Open.

This is an open access article licensed under the terms of the Creative Commons Attribution Non-Commercial License (http: //creativecommons.org/licenses/by$\mathrm{nc} / 3.0 /$ ), which permits unrestricted, non-commercial use, distribution and reproduction in any medium, provided the work is properly cited. 